\title{
Management of patients with atrial fibrillation at high risk of stroke: current treatment options
}

This article was published in the following Dove Press journal:

Research Reports in Clinical Cardiology

22 June 2012

Number of times this article has been viewed

\section{Duncan Edwards \\ Keara Harris \\ Jonathan Mant}

Primary Care Unit, University of Cambridge, Cambridge, UK
Correspondence: Duncan Edwards Primary Care Unit, University of Cambridge, Forvie Site, Cambridge CB2 OSR, UK Tel +44 I 223742088 Fax +44I223 7625I5 Email dae3।@medschl.cam.ac.uk

\begin{abstract}
Atrial fibrillation (AF) is common, and is associated with an increased risk of stroke. Patients' absolute risk of stroke depends on the presence or absence of additional risk factors as well as AF, including prior thromboembolism, increased age, hypertension, diabetes, structural heart disease, and female sex. The risk to benefit ratio of stroke prevention therapy differs according to the patients' absolute risk. There is evidence that even those with an estimated annual stroke risk of $2 \%-4 \%$, who were once classified as medium risk, would benefit from anticoagulation and should be included in an expanded high-risk category. Alternatives to anticoagulation include the restoration of sinus rhythm and left atrial appendage surgery, but these may not be suitable for many high-risk patients with comorbidities. Antiplatelets are substantially less effective than anticoagulation and cause similar rates of bleeding. Self-monitoring and computerized decision support increases the time in therapeutic range and effectiveness of vitamin $\mathrm{K}$ antagonists. Novel oral anticoagulants including dabigatran, rivoraxaban, and apixaban have been shown to be noninferior to warfarin, do not require monitoring, and increase the prescribing options for stroke prevention in AF.
\end{abstract}

Keywords: stroke prevention, atrial fibrillation, anticoagulants, primary prevention

\section{Introduction}

Atrial fibrillation (AF) is associated with a five-times increased risk of stroke ${ }^{1}$ and currently accounts for at least $15 \%-20 \%$ of ischemic strokes in the United States. ${ }^{2}$ Prevalence rises with age and is increasing as the population ages; at least $6 \%$ of Medicare patients $\geq 65$ years currently have $\mathrm{AF}^{3}$ and by 2050 it is estimated that up to 16 million adults in the United States will have AF. ${ }^{4}$ This article focuses on how to treat patients with AF who are at high risk of stroke, exploring the changing practical definition of high risk, discussing alternatives to the current gold standard treatment of anticoagulation - including cardioversion, surgery, and antiplatelets - before focusing on the best use of novel anticoagulants and vitamin $\mathrm{K}$ antagonists.

\section{Defining high risk}

In the recent past, clinicians segregated the risk of stroke in patients with AF into low, medium, and high risk, with only patients with estimated risk of stroke of greater than approximately 5\% per year deemed to be at high risk and routinely appropriate for anticoagulation (see Figure 1A). ${ }^{5}$ Patient risk level was established based on the presence or absence of additional risk factors for stroke, the most evidence-based of which include prior stroke/transient ischemic attack (TIA), prior thromboembolism, increased age, hypertension, diabetes, structural heart disease, and 


\section{A}

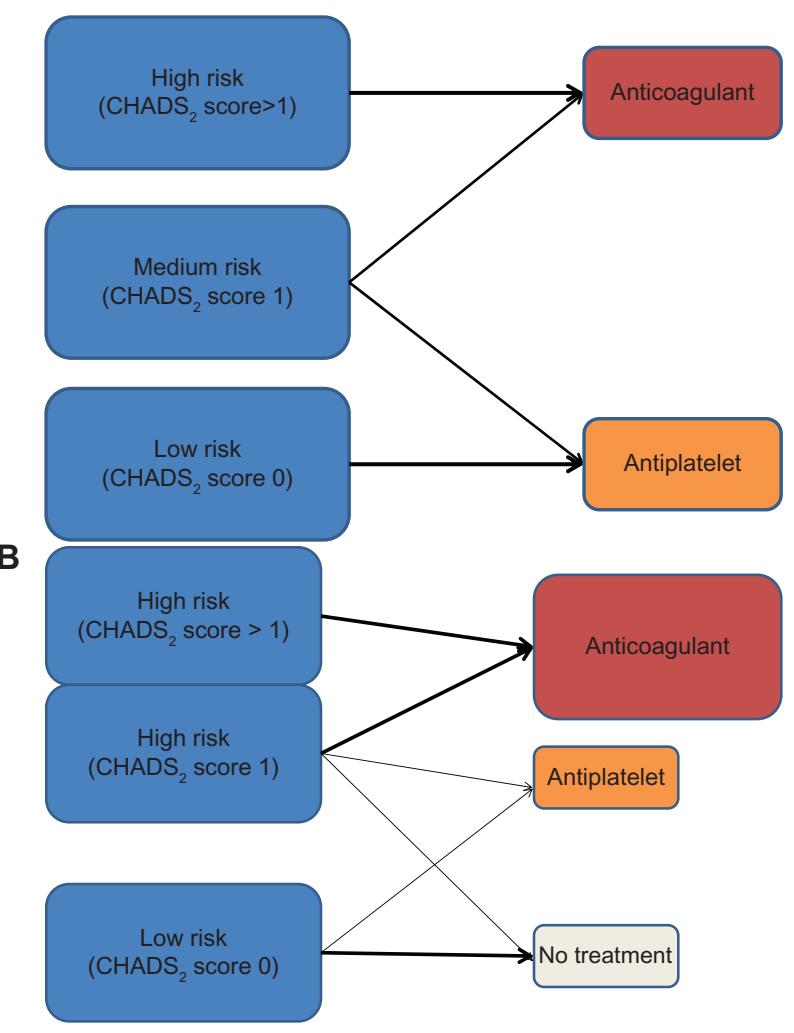

Figure I The increased role for anticoagulation. (A) Previous guidelines for management of high risk atrial fibrillation (eg, the 2006 NICE guideline) emphasized high, medium, and low risk with a choice of anticoagulant or antiplatelet for those at medium risk. ${ }^{5}$ (B) Recent evidence suggest more patients benefit from being treated as "high risk" with an anticoagulant.

Note: Aspirin has a reduced role.

Abbreviations: $\mathrm{CHADS}_{2}$, Congestive heart failure, Hypertension, Age $>75$ years, Diabetes mellitus, and prior Stroke or transient ischemic attack; NICE, National Institute for Health and Clinical Excellence.

female sex. ${ }^{6-8}$ Various risk stratification scores have been developed to combine some of these risk factors, of which the most prominent are $\mathrm{CHADS}_{2}$ (Congestive heart failure, Hypertension, Age $>75$ years, Diabetes mellitus, and prior Stroke or transient ischemic attack $)^{9}$ and $\mathrm{CHA}_{2} \mathrm{DS}_{2}-\mathrm{VASc}$ (Vascular disease, Age $>65$ years, Sex category) ${ }^{10}$ (see Table 1 and Figure 2). Patients with $\mathrm{CHADS}_{2}$ scores of 1 and an estimated stroke risk below $2 \%-4 \%$ were often advised that the side effects of treatment (primarily bleeding) did not justify anticoagulant treatment.

Recent studies provide stronger evidence for clinically significant and safe stroke prevention when anticoagulation is used in patients who were once deemed to be medium risk. The BAFTA study (see Table 2 for an explanation of trial acronyms) demonstrated a relative risk (RR) of 0.48 (95\% confidence interval [CI]: $0.28-0.80$, absolute yearly risk $=1.8 \%$ vs $3.8 \%$ ) for all stroke and systemic embolus in patients aged over 75 years treated with warfarin versus
Table I Stroke risk stratification schemes for patients with atrial fibrillation, using the $\mathrm{CHADS}_{2}$ and $\mathrm{CHA}_{2} \mathrm{DS}_{2}$-VASc scores

\author{
CHADS $_{2}$ \\ Congestive heart failure \\ Hypertension \\ Age $>75$ years \\ Diabetes \\ Previous Stroke or TIA (2 points) \\ $\mathrm{CHA}_{2} \mathrm{DS}_{2}$-VASc modifications and additions \\ Age $>75$ years (2 points) \\ Vascular disease (previous myocardial infarction, peripheral artery \\ disease or aortic plaque) \\ Age $>65$ years (I point) \\ Sex category (female) \\ Note: Each clinical characteristic scores I point unless otherwise indicated. \\ Abbreviation: TIA, transient ischemic attack.
}

aspirin. This relative and absolute risk reduction was sustained in patients with $\mathrm{CHADS}_{2}$ scores of $1-2(0.47 \mathrm{RR}$, $95 \%$ CI: $0.23-0.89$, absolute yearly risk $=1.5 \%$ vs $3.3 \%$ ) and bleeding rates were similar in both groups. ${ }^{11}$ The ACTIVE-W (Atrial fibrillation Clopidogrel Trial with Irbesartan for prevention of Vascular Events) trial, which compared warfarin with the combination of aspirin and clopidogrel, demonstrated significant stroke reduction in patients with a $\mathrm{CHADS}_{2}$ score of 1 treated with warfarin $(0.43 \%$ vs $1.25 \%) .{ }^{12}$ The AVERROES study, which compared the anticoagulant apixaban with aspirin, demonstrated a clinically relevant reduction in stroke or systemic embolism in patients with $\mathrm{CHADS}_{2}$ scores of just $0-1$, with no increase in major bleeding (absolute risk $0.9 \%$ vs $1.6 \%$, a difference which was not significant). ${ }^{13}$ Complicated risk stratification may therefore be unnecessary, and more patients should be treated as high risk even if their estimated annual risk estimate is $2 \%-4 \%$ (see Figure 1B). This is consistent with research into patient attitudes that suggests that the majority of patients would choose warfarin even if it reduced their stroke risk by just $1 \%$ per annum..$^{14,15}$

In addition, the $\mathrm{CHADS}_{2}$ and $\mathrm{CHA}_{2} \mathrm{DS}_{2}$-VASc scores predict stroke risk poorly, producing c-statistics better than chance but lower than those achieved by other cardiovascular risk stratification scores (ranging from 0.55 to 0.62 when applied to the BAFTA cohort). ${ }^{16}$ Therefore the current European Society of Cardiology guidelines suggest the use of anticoagulation over aspirin in patients with $\mathrm{AF}$ who are greater than 75 years of age or who have previously had a stroke/TIA, the two factors most strongly correlated with future stroke risk. ${ }^{8,17}$ They also advise a preference for anticoagulation in patients with AF with any risk factor for stroke (ie, any of the individual risk factors listed in the 


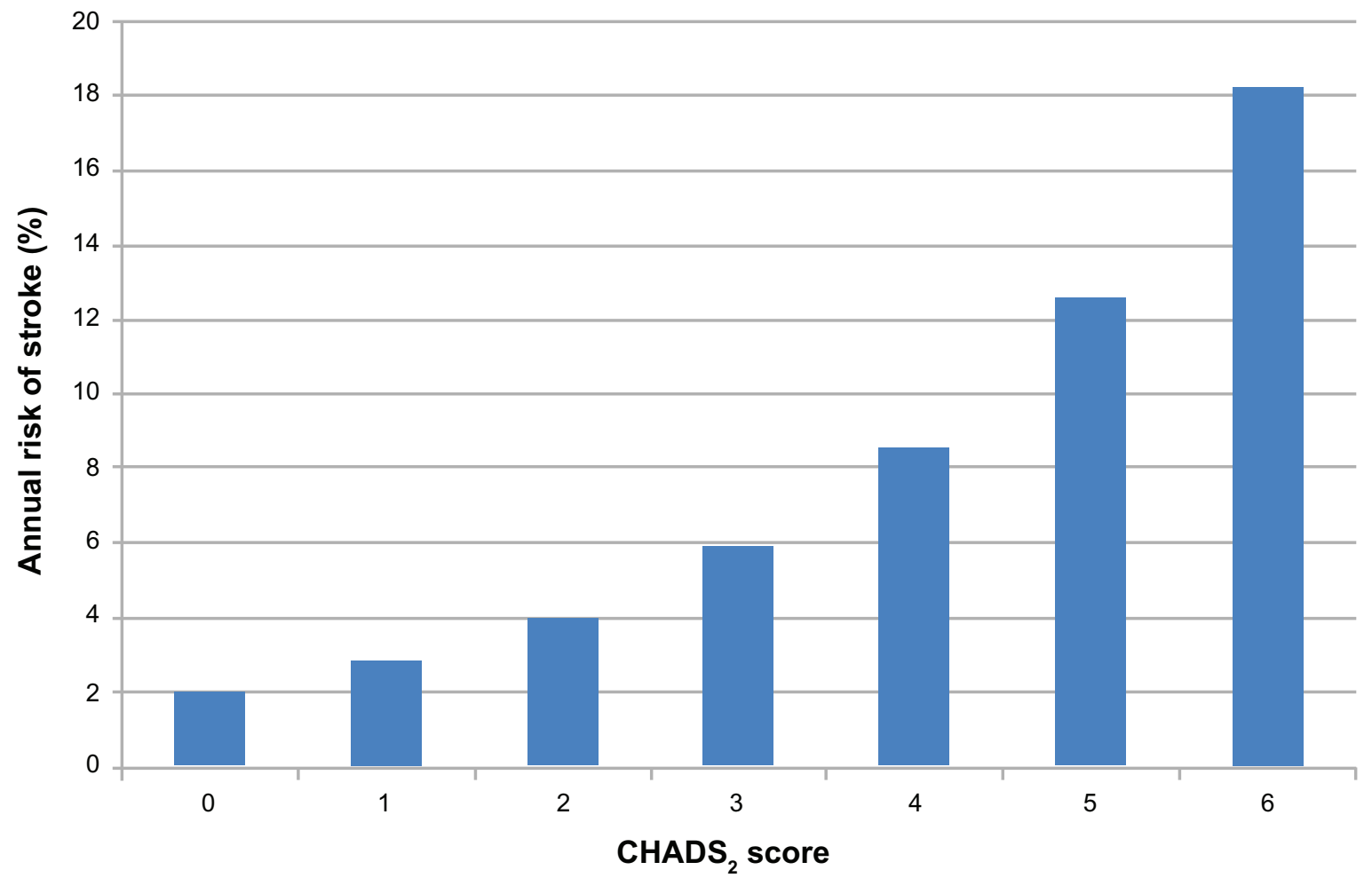

Figure $2 \mathrm{CHADS}_{2}$ and annual untreated risk of stroke.

Note: Produced using data presented in Gage BF, Waterman AD, Shannon W, Boechler M, Rich MW, Radford MJ. Validation of clinical classification schemes for predicting stroke: results from the National Registry of Atrial Fibrillation. JAMA. 2001;285(22):2864-2870.9

Abbreviation: $\mathrm{CHADS}_{2}$, Congestive heart failure, Hypertension, Age $>75$ years, Diabetes mellitus, and prior Stroke or transient ischemic attack.

$\mathrm{CHA}_{2} \mathrm{DS}_{2}$-VASc score). ${ }^{18}$ However, for patients with just one risk factor, the absolute benefit of treatment will be lower, and so some patients may prefer not to be treated, ${ }^{14,15}$ and some treatments may not be cost-effective. The absolute risk of stroke may also be lower in patients with very occasional asymptomatic paroxysmal AF that can be detected with new, highly sensitive technologies, ${ }^{19,20}$ although current guidelines continue to suggest treating stroke risk similarly in all patients with persistent and paroxysmal AF. ${ }^{18,21}$

\section{Alternatives to anticoagulation: restoration of sinus rhythm}

Restoration and maintenance of sinus rhythm through medication (sometimes combined with electrical cardioversion) or through catheter ablation has not been shown to be an effective alternative to anticoagulation for patients at high risk of stroke, but may be a useful addition in patients in persistent or paroxysmal AF as maintenance of sinus rhythm is most likely to be successful in this group. In 2002, the AFFIRM (Atrial Fibrillation Follow-up Investigation of Rhythm Management) randomized controlled trial demonstrated a nonsignificant increase in both death and stroke in patients randomized to a rhythm- (as opposed to rate-) controlling strategy. ${ }^{22}$ This may be related to side effects of rhythm-controlling medications and the fact that only $62.6 \%$ of patients in the rhythm control arm were actually in sinus rhythm at 3 years. Indeed, a post-hoc analysis demonstrated an association between successful maintenance of sinus rhythm and survival. ${ }^{23}$ While this may merely be an association without causation, it supports the notion that an effective sinus rhythm maintenance strategy could add to survival and stroke prevention in patients with AF.

The ATHENA trial that was published in 2009 treated 4628 patients aged over 70 years with persistent or paroxysmal $\mathrm{AF}$ and additional risk factors using the new antiarrhythmic dronedarone versus placebo, and demonstrated a statistically significant reduction in annual deaths from cardiovascular causes over a mean follow-up of 21 months $(2.7 \%$ vs $3.9 \%$, $\mathrm{RR}=0.71 ; 95 \% \mathrm{CI}: 0.51-0.98) .{ }^{24}$ This reduction was driven by a reduction in deaths from cardiac arrhythmia $(1.1 \%$ vs $2.1 \%$ ), and there was no reduction in death from noncardiac vascular causes (predominantly stroke; $0.9 \%$ vs $1.0 \%$ ). As in the AFFIRM study, patients were permitted to continue on their anticoagulant medication regardless of whether sinus rhythm was achieved. Conversely, dronedarone resulted in a statistically significant increase in cardiovascular deaths 
Table 2 Trial acronyms, main study publication date, and full names

ACTIVE W (2006) Atrial fibrillation clopidogrel trial with irbesartan and ACTIVE A for prevention of vascular events

(2009)

AFFIRM (2002) Atrial fibrillation follow-up investigation of rhythm management

ARISTOTLE Apixaban for reduction in stroke and other

(20II) thromboembolic events in atrial fibrillation

ATHENA (2009) A placebo-controlled, double-blind, parallel arm trial to assess the efficacy of dronedarone $400 \mathrm{mg}$ bid for the prevention of cardiovascular hospitalisation or death from any cause in patients with atrial fibrillation/flutter

AVERROES

(20II)

BAFTA (2007) ENGAGE AF-TIMI

(20I2)

PALLAS (2011)

PROTECT-AF

(2009)

RE-LY (2009)

ROCKET-AF (20II)

Apixaban versus acetylsalicylic acid to prevent strokes

Birmingham atrial fibrillation treatment of the aged Global study to assess the safety and effectiveness of DU- I 76b vs standard practice of dosing with warfarin in patients with atrial fibrillation Permanent atrial fibrillation outcome study using dronedarone on top of standard therapy System for embolic protection in patients with atrial fibrillation

Randomized evaluation of long-term anticoagulation therapy

Rivaroxaban once daily oral direct factor Xa inhibition compared with vitamin $\mathrm{K}$ antagonism for prevention of stroke and embolism trial in atrial fibrillation

and strokes when it was trialed in patients in permanent $\mathrm{AF}$, in whom it increased rates of sinus rhythm by just $2 \%$ at 4 months. ${ }^{25}$

Catheter ablation, in which tissue-generating or -propagating aberrant electrical pathways in the left atrium are destroyed, has recently become a popular technique for restoring and maintaining sinus rhythm. It is more effective than medication at maintaining sinus rhythm, ${ }^{26}$ and is associated with lower rates of stroke when registries of patients who have experienced ablation are compared with equivalent cohorts of patients who have not been ablated. ${ }^{27,28}$ However, large randomized controlled trials comparing ablation versus nonablation have not been undertaken, and the registries that are our best source of evidence on outcomes contain few high-risk patients (the 1273 patients in the Euro Heart Registry had a mean age of $58 \pm 11$ years and mean $\mathrm{CHADS}_{2}$ score of $\left.0.9 \pm 0.7\right) .{ }^{28}$ Immediate complication rates are approximately $5 \%$ even in these lower risk patients. In the Euro Heart Registry dataset, $5.4 \%$ of patients experienced a major complication including tamponade (3.1\%), hematoma prolonging hospital stay $(2.1 \%)$, stroke or TIA $(0.7 \%)$, and death $(0.1 \%)$.

Stroke risk remains high in older and higher-risk patients after restoration of sinus rhythm. This is because there is a high chance of AF returning with all current methods, and the other risk factors for stroke remain. In patients at high risk of stroke, restoration of sinus rhythm therefore remains a symptomcontrol strategy rather than a stroke-prevention strategy. In most cases, anticoagulation should be continued even if sinus rhythm is achieved.

\section{Alternatives to anticoagulation: left atrial appendage surgery}

A review of echocardiographic, autopsy, and intra-operative findings suggests that approximately $91 \%$ of left atrial thrombi are located in the left atrial appendage in patients with nonrheumatic $\mathrm{AF}^{29}$ Surgical closure of the left atrial appendage has therefore been tested as an alternative to anticoagulation. The PROTECT-AF study involved 707 patients with at least one additional risk factor for stroke, comparing percutaneous left atrial appendage closure and subsequent discontinuation of warfarin with warfarin treatment with a target international normalized ratio (INR) of 2.0-3.0. ${ }^{30}$ After a mean follow-up of 18 months, surgery was found to be noninferior to warfarin $(2.3 \%$ annual rate of stroke, cardiovascular death and systemic embolism vs $3.2 \%$ on warfarin, $\mathrm{RR}=0.62 ; 95 \% \mathrm{CI}$ : $0.35-1.25)$, but resulted in significantly more immediate complications, particularly pericardial effusion ( $4.8 \%$ of patients) and device embolization $(0.6 \%$ of patients) in the surgical group. A longer follow up period may favor the operative approach if it continues to be effective, as the immediate complications may eventually be outweighed by lower long-term bleeding. Additionally, increased surgical experience is likely to improve results. Longer term randomized evidence is not currently available, ${ }^{31}$ although observational data show that stroke rates remain reduced for at least 5 years. ${ }^{32}$

\section{Alternatives to anticoagulation: antiplatelets}

Oral anticoagulation with a vitamin $\mathrm{K}$ antagonist such as warfarin is superior to aspirin at preventing stroke in AF. A practical rule of thumb is that warfarin reduces stroke RR by $60 \%$, aspirin by $20 \%$, and warfarin over aspirin by $40 \%$. The latter figure is backed by a meta-analysis of twelve trials with 12,693 participants that demonstrated a RR reduction of $39 \%$ (95\% CI: 22\%-52\%). ${ }^{33}$ A randomized controlled trial of 973 patients in AF aged over 75 years in a primary care setting found that oral anticoagulation was more effective than aspirin, and equivalently safe. ${ }^{11}$

Dual antiplatelets have also been compared with anticoagulation. The ACTIVE W trial compared oral 
anticoagulation with clopidogrel plus aspirin in 6706 patients in AF who had at least one additional risk factor for stroke. ${ }^{34}$ Dual antiplatelets were found to be both less effective (primary endpoint of stroke, systemic embolus, myocardial infarction, or vascular death in $5.6 \%$ of patients per annum when on antiplatelets vs $3.9 \%$ when on anticoagulation, $\mathrm{RR}=1.4 ; 95 \% \mathrm{CI}: 1.2-1.8)$ and to cause slightly more bleeding $(2.4 \%$ vs $2.2 \%$ for major bleeding, $\mathrm{RR}=1.1 ; 95 \% \mathrm{CI}$ : $0.8-1.4 ; 13.6 \%$ vs $11.4 \%$ for minor bleeding, $\mathrm{RR}=1.2 ; 95 \%$ CI: 1.1-1.3). Analysis of the cohort of all 118,606 Danish patients surviving AF hospitalization between 1997 and 2006 also demonstrates that combined aspirin and clopidogrel is associated with a higher risk of bleeding than warfarin alone $(\mathrm{RR}=1.66 ; 95 \% \mathrm{CI}: 1.34-2.04) .{ }^{35}$ Anticoagulation is thus superior to dual antiplatelets in efficacy and safety.

The question can arise of how to manage a patient at high risk of stroke for whom there is a contraindication to anticoagulation such as allergy or inability to monitor treatment. The ACTIVE A trial compared aspirin and clopidogrel to aspirin alone in 7554 patients in AF for whom warfarin was deemed unsuitable and with at least one additional risk factor for stroke, and showed only a marginal decrease in stroke from the addition of clopidogrel to aspirin (2.4\% vs 3.3\% per year; $\mathrm{RR}=0.72 ; 95 \% \mathrm{CI}: 0.62-0.83$ ) at the expense of increased major bleeding (2.0\% vs $1.3 \%$ per year; RR $=1.6$; 95\% CI: 1.3-1.9). ${ }^{36}$ American guidelines therefore suggest that if anticoagulation is contraindicated, aspirin alone should always be used, ${ }^{37}$ whereas European guidelines permit consideration of dual antiplatelets in this circumstance. ${ }^{18}$ Since patients value stroke prevention over major bleeding prevention, ${ }^{11}$ the latter approach is perhaps more rational.

The AVERROES study is the first Phase III trial to compare a novel anticoagulant which does not require monitoring versus aspirin. ${ }^{13}$ AVERROES compared the factor Xa inhibitor apixaban with aspirin in 5599 patients in AF who were deemed unsuitable for warfarin, and found a substantially lower rate of stroke or systemic embolus in the apixaban group ( $1.6 \%$ vs $3.7 \%$ per year; $R R=0.45 ; 95 \%$ $\mathrm{CI}=0.32-0.62)$ with an equivalent rate of major bleeding ( $1.4 \%$ vs $1.2 \%$ per year). Apixaban and other novel anticoagulants should end the need to settle for antiplatelets in patients at high risk of stroke.

Care should also be taken to avoid the use of anti-platelets in addition to anticoagulation unless there is a clear indication, such as for a limited period after acute coronary syndrome or percutaneous coronary intervention, or a prosthetic heart valve. ${ }^{18,38}$ There is good evidence that warfarin is at least as effective as aspirin in preventing vascular events following myocardial infarction, ${ }^{39}$ while the Danish cohort demonstrated a doubled risk of bleeding in patients on aspirin and warfarin dual therapy, and a more than three-fold risk in patients on clopidogrel-warfarin dual therapy or aspirin-clopidogrel-warfarin triple therapy. ${ }^{35}$ Nevertheless, $20 \%-40 \%$ of patients in the Danish cohort and in recent randomized controlled trials were taking an antiplatelet in addition to their anticoagulant. ${ }^{35,40-42}$

\section{New anticoagulant medications}

Numerous new anticoagulants have been or are being tested against warfarin for stroke prevention in AF (Table 3 shows those with Phase III studies underway or that have recently been published). These are either activated factor Xa inhibitors (including rivaroxaban, apixaban, edoxaban, betrixaban, and YM150) or direct thrombin inhibitors (dabigatran, AZD0837) and have the advantage of not requiring monitoring. ${ }^{18}$ Promising anticoagulants of both classes have failed due to safety concerns, the activated factor $\mathrm{Xa}$ inhibitor idraparinux due to a high bleeding risk, ${ }^{43}$ and the direct thrombin inhibitor ximelagatran due to concerns about liver damage. ${ }^{44}$ However, results from the RE-LY, ${ }^{40}$ ROCKET-AF, ${ }^{42}$ and ARISTOTLE ${ }^{41}$ studies that compare dabigatran, rivaroxaban, and apixaban favorably with warfarin have recently been published (see Tables 4 and 5).

\section{Dabigatran versus warfarin - the RE-LY study}

The RE-LY study randomized 18,113 patients in AF to one of three equally sized groups: warfarin (target INR 2-3, as in the ROCKET-AF and ARISTOTLE studies), dabigatran etexilate $110 \mathrm{mg}$ twice daily, or dabigatran etexilate $150 \mathrm{mg}$ twice daily. ${ }^{40}$ The majority of patients were at high risk of stroke, with $69.1 \%$ having two risk factors for stroke (see Tables 3 and 4). Although the dose of dabigatran was blinded for patients in the two dabigatran groups, allocation to warfarin was open label. Median follow-up was 2 years (similar to ROCKET-AF and ARISTOLE, see Table 3) and the primary efficacy endpoint was stroke or systemic embolism (as in ROCKET-AF and ARISTOTLE). Reductions in hemorrhagic stroke and intracranial hemorrhage were significant and substantial for both doses of dabigatran (as in ROCKET-AF and ARISTOTLE). The headline conclusion from RE-LY is that higher dose dabigatran was associated with lower risk of stroke or systemic embolism, with a similar risk of major hemorrhage, whereas lower dose dabigatran was associated with a similar risk of stroke or 


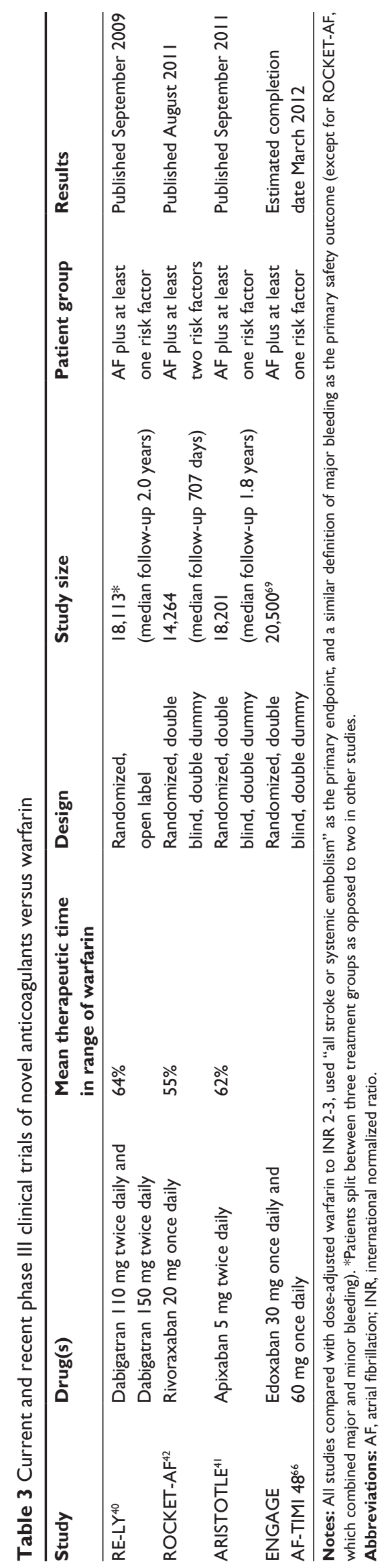

systemic embolism, with a lower risk of major hemorrhage (see Table 5).

\section{Rivaroxaban versus warfarin - the ROCKET-AF study}

The ROCKET-AF study randomized 14,264 patients to either warfarin or rivaroxaban $20 \mathrm{mg}$ once daily. ${ }^{42}$ All patients were at high risk of stroke (two risk factors for stroke were entry criteria) and therefore patients had substantial levels of preexisting disease (see Tables 3 and 4). Both the ROCKET-AF and ARISTOTLE studies used a double-dummy design with dummy INR results given to the nonwarfarin group. The ROCKET-AF study was the least encouraging of the three studies. Rivaroxaban was associated with a small reduction in risk of stroke or systemic embolism (with this reduction being nonsignificant when analyzed on an intention-to-treat basis) and was also associated with a very small, nonsignificant increase in major bleeding (see Table 5).

\section{Apixaban versus warfarin - the ARISTOTLE study}

The ARISTOTLE study randomized 18,201 patients to either warfarin or apixaban $5 \mathrm{mg}$ twice daily. ${ }^{41}$ Some $66 \%$ of patients had two additional risk factors for stroke, and all patients had at least one additional risk factor (see Tables 3 and 4). Apixaban was associated with both a lower risk of stroke or systemic embolism and with a lower risk of major hemorrhage (see Table 5).

\section{Conclusions from RE-LY, ROCKET-AF, and ARISTOTLE}

Precise comparison between dabigatran, rivaroxaban, and apixaban would require a direct comparison randomized controlled trial, which is unlikely to happen. Major differences between the trials include the older, sicker patient group in ROCKET-AF (which favored higher rates of outcomes) and the lack of blinding in RE-LY. However, since there are now three very large studies comparing novel anticoagulants to warfarin (INR range 2-3) in similar populations, it is possible to draw some broad conclusions about the efficacy, safety, and tolerability of novel anticoagulants.

In terms of efficacy, novel anticoagulants outperformed warfarin with regard to the primary outcome of preventing overall stroke and systemic embolism. Dabigatran resulted in the largest reduction, although the numbers needed to treat were 172 versus warfarin. Furthermore, all 
Table 4 Summary of baseline characteristics of patients in RE-LY, ${ }^{40}$ ROCKET-AF, ${ }^{42}$ and ARISTOTLE ${ }^{41}$

\begin{tabular}{|c|c|c|c|}
\hline & RE-LY & ROCKET-AF & ARISTOTLE \\
\hline Patients in warfarin group & 6022 & 7133 & 9081 \\
\hline Mean age (standard deviation) & $71.5(8.8)$ & $73(65-78$ IQ) & $70(63-76 \mathrm{IQ})$ \\
\hline Female (\%) & 36.7 & 39.7 & 35.0 \\
\hline Mean $\mathrm{CHADS}_{2}(\mathrm{SD})$ & $2.1(1 . I)$ & $3.46(0.95)$ & $2.1(1.1)$ \\
\hline $\mathrm{CHADS}_{2}$ I (\%) & 30.9 & Zero & 34.0 \\
\hline $\mathrm{CHADS}_{2} 2(\%)$ & 37.0 & 13.1 & 35.8 \\
\hline $\mathrm{CHADS}_{2} 3-6(\%)$ & 32.1 & 86.9 & 30.2 \\
\hline Prior stroke/TIA/SE (\%) & 19.8 & 54.6 & 19.7 \\
\hline Prior MI (\%) & 16.1 & 18.0 & 13.9 \\
\hline Heart failure (\%) & 31.9 & 62.3 & 35.5 (or reduced LVEF) \\
\hline Diabetes (\%) & 23.4 & 39.5 & 24.9 \\
\hline Hypertension (\%) & 78.9 & 90.8 & 87.6 \\
\hline Mean systolic $\mathrm{mmHg}$ (SD or interquartile) & |3|.2 (I7.4 SD) & I30 (I20-|40 IQ) & I30 (I20-I40 IQ) \\
\hline \multirow[t]{2}{*}{ Discontinuation rate at study end } & $21.2 \%$ dabigatran & $23.7 \%$ rivaroxaban & $25.3 \%$ apixaban \\
\hline & $16.6 \%$ warfarin & $\begin{array}{l}22.2 \% \text { warfarin } \\
\text { (before an endpoint/termination) }\end{array}$ & $27.5 \%$ warfarin \\
\hline
\end{tabular}

Abbreviations: $\mathrm{CHADS}_{2}$, Congestive heart failure, Hypertension, Age $>75$ years, Diabetes mellitus, and prior Stroke or transient ischemic attack; IQ, interquartile range; LVEF, left ventricle ejection fraction; MI, myocardial infarction; SD, standard deviation; SE, systemic embolism; TIA, transient ischemic attack.

novel anticoagulants reduced annual all-cause mortality by $9 \%-15 \%$, although this reduction was only statistically significant in the case of apixaban (see Table 5).

With regard to safety, both dabigatran and apixaban resulted in less major bleeding than warfarin (this result was significant for apixaban $5 \mathrm{mg}$ twice daily, but not for dabigatran $150 \mathrm{mg}$ twice daily) and none of the novel anticoagulants were associated with increased liver impairment. A particular concern with dabigatran was a higher rate of myocardial infarction (see Table 5), which has been confirmed in a metaanalysis of trials including dabigatran for other clinical indications than $\mathrm{AF}^{45}$ This may be because warfarin and other anticoagulants prevent nonembolic vascular events; ${ }^{39}$ it is noted that only one of the seven trials included in the meta-analysis was against placebo. Increased risk of myocardial infarction was not shown for apixaban or rivaroxaban. Given that dabigatran $150 \mathrm{mg}$ twice daily was associated with the greatest stroke reduction, clinicians might use dabigatran in patients without strong risk factors for myocardial infarction, and use an alternate anticoagulant such as apixaban or warfarin in patients at high risk of myocardial infarction. Similarly, the fact that dabigatran is largely renally excreted will favor the use of apixaban and warfarin in patients with severe renal impairment. Warfarin remains the treatment of choice for patients with hemodynamically significant valve disease, a prosthetic valve, or advanced liver disease due to an absence of experience with novel anticoagulants in these groups. ${ }^{46}$

Novel anticoagulants do not require monitoring, which is a significant advantage with regard to tolerability over warfarin. In the RE-LY, ROCKET-AF, and ARISTOTLE trials, however, discontinuation rates were similar for the novel anticoagulants and warfarin, and in fact were slightly higher for dabigatran and rivaroxaban versus warfarin (see Table 4). Crucially, being part of a trial will have encouraged continuation in all groups (as does regular INR monitoring for patients outside of trials), so it will be important to check that cohorts of patients on novel anticoagulants outside of a trial setting continue their anticoagulant medications at rates similar to warfarin, especially given the shorter half-lives of novel anticoagulants.

\section{Improving anticoagulation with vitamin $K$ antagonists}

Anticoagulation with vitamin $\mathrm{K}$ antagonists such as warfarin has for decades been the most effective preventive strategy in patients with AF at high risk of stroke. A systematic review of six trials containing 2900 patients suggests that adjusteddose warfarin vs placebo reduces stroke by $64 \%$ (95\% CI: $49 \%-74 \%$ ), and this has been used as the gold standard when describing recent competing strategies. Recent guidelines and trials uniformly target an INR of 2.5 with a range of 2-3, ${ }^{18,21,40-42}$ as ischemic stroke increases below this level and major bleeding increases above it (see Figure 3). Drawbacks of vitamin $\mathrm{K}$ antagonists include an increased risk of bleeding and a narrow therapeutic range, which necessitate inconvenient monitoring and are exacerbated by drug and food interactions, a further source of disruption to patients' lives.

A number of scores have been developed to determine bleeding risk in the hope of identifying patients at increased risk of bleeding who should avoid vitamin $\mathrm{K}$ antagonists; these include HAS-BLED ${ }^{47}$ and HEMORR2HAGES. ${ }^{48}$ HAS-BLED incorporates hypertension (>160 mmHg systolic), significant liver impairment, 
Table 5 Summary results of RE-LY, ${ }^{40,67}$ ROCKET-AF, ${ }^{42}$ and ARISTOTLE ${ }^{41}$

\begin{tabular}{|c|c|c|c|c|c|}
\hline \multirow{2}{*}{$\begin{array}{l}\text { Outcome } \\
\text { (\%/year) }\end{array}$} & \multicolumn{3}{|c|}{ RE-LY (vs dabigatran I 50 mg bd) } & \multicolumn{2}{|c|}{ RE-LY (vs dabigatran I I 0 mg bd) } \\
\hline & $\begin{array}{l}\text { Dabigatran } 150 \mathrm{mg} \\
\text { twice daily } \\
\text { (6076 patients) }\end{array}$ & $\begin{array}{l}\text { Warfarin } \\
(6022)\end{array}$ & $\begin{array}{l}\text { Dabigatran } 150 \text { mg } \\
\text { twice daily vs } \\
\text { warfarin }\end{array}$ & $\begin{array}{l}\text { Dabigatran II } 0 \mathrm{mg} \\
(60 \mid 5)\end{array}$ & $\begin{array}{l}\text { Dabigatran II } 0 \mathrm{mg} \\
\text { twice daily vs } \\
\text { warfarin }\end{array}$ \\
\hline $\begin{array}{l}\text { Stroke or systemic } \\
\text { embolism }\end{array}$ & 1.11 & 1.71 & $0.65(0.52-0.8 I)$ & 1.54 & $0.90(0.74-1.10)$ \\
\hline All stroke & 1.01 & 1.57 & $0.64(0.5 \mathrm{I}-0.8 \mathrm{I})$ & 1.44 & $0.92(0.74-1.13)$ \\
\hline Hemorrhagic stroke & 0.10 & 0.38 & $0.26(0.14-0.49)$ & 0.12 & $0.31(0.17-0.56)$ \\
\hline $\begin{array}{l}\text { Ischemic or unspecified } \\
\text { stroke }\end{array}$ & 0.92 & 1.20 & $0.76(0.60-0.98)$ & 1.34 & I.II (0.89-I.40) \\
\hline Myocardial infarction & 0.81 & 0.64 & $\mathrm{I} .27(0.94-\mid .7 \mathrm{I})$ & 0.82 & $1.29(0.96-1.75)$ \\
\hline $\begin{array}{l}\text { Death from vascular } \\
\text { causes }\end{array}$ & 2.28 & 2.69 & $0.85(0.72-0.99)$ & 2.43 & $0.90(0.77-1.06)$ \\
\hline Death from all causes & 3.64 & 4.13 & $0.88(0.77-1.00)$ & 3.75 & $0.91(0.80-1.03)$ \\
\hline Major bleeding & 3.32 & 3.57 & $0.93(0.81-1.07)$ & 2.87 & $0.80(0.70-0.93)$ \\
\hline $\begin{array}{l}\text { Intracranial } \\
\text { hemorrhage }\end{array}$ & 0.30 & 0.74 & $0.40(0.27-0.60)$ & 0.23 & $0.31(0.20-0.47)$ \\
\hline
\end{tabular}

creatinine $>200 \mu \mathrm{mol} / \mathrm{L}$, stroke, bleeding history or disposition, labile INR (time in therapeutic range $<60 \%$ ), age over 65 years, concomitant use of alcohol, and concomitant use of antiplatelets or NSAIDs. Unfortunately, many of these factors are also risk factors for stroke, and patients at higher risk of bleeding are at higher risk of stroke. It has therefore been suggested that oral anticoagulation be prescribed unless the HAS-BLED score exceeds the $\mathrm{CHADS}_{2}$ score ${ }^{47}$ however, applying this rule to 1580 patients with AF in the Euro Heart Survey would have resulted in just four patients who had a major bleed not having had anticoagulation, whereas 34 patients who did not have a major bleed would have had their anticoagulation withheld. ${ }^{47}$ The European Society of Cardiology suggests using "some caution and regular review" if a patient has three or more risk factors for bleeding. ${ }^{18}$ The net impact of bleeding risk scores remains uncertain, and

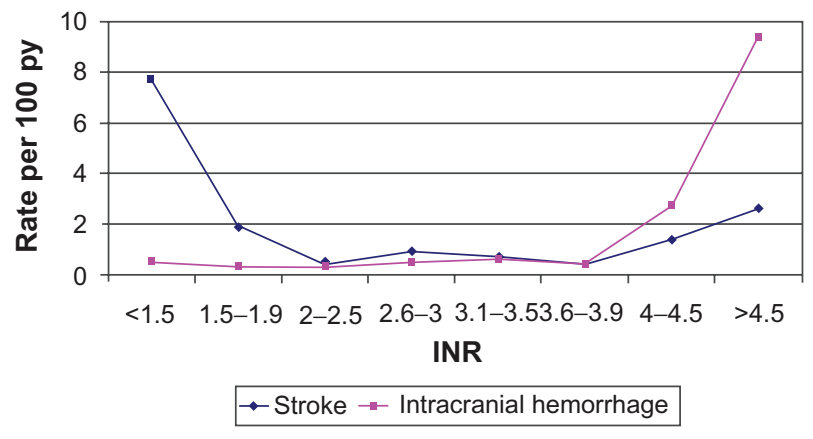

Figure 3 Rates of ischemic stroke and intracranial hemorrhage in a cohort study of 13,000 patients in atrial fibrillation receiving vitamin $\mathrm{K}$ antagonists, by international normalized ratio at time of the event.

Note: Produced using data presented in Hylek EM, Go AS, Chang Y, et al. Effect of intensity of oral anticoagulation on stroke severity and mortality in atrial fibrillation. $N$ Engl J Med. 2003;349(I I):1019-1026. ${ }^{68}$

Abbreviations: INR, international normalized ratio; py, per year. these have not been tested prospectively. It is important to remember that patients at high risk of AF may place more value on the avoidance of stroke and less value on the avoidance of bleeding than the physicians who treat them, ${ }^{14}$ and that undertreatment of high risk $\mathrm{AF}$ is a far bigger problem than inappropriate treatment: a recent UK primary care database showed that only $51.4 \%$ of patients with $\mathrm{CHADS}_{2}>1$ were receiving warfarin, and of the $48.6 \%$ who were undertreated, only $27 \%$ had an absolute contraindication. ${ }^{49}$

Typical (nontrial) patients, who are more likely to be frail and medically unstable, may be at particularly high risk of bleeding soon after initiation: a cohort of 472 patients with mean age of 77 years (older than in most trials) and therapeutic time in range (TTR) of 58\% (equivalent to many trials), demonstrated a $7.2 \%(95 \%$ CI: $4.9 \%-10.6 \%)$ rate of major bleeding within 1 year of initiation of warfarin. ${ }^{50}$ This rate is substantially higher than that shown in trials (see Table 5), including in trial patients initiated on warfarin: in the RE-LY study, warfarin-naïve patients assigned to warfarin experienced exactly the same rates of major bleeding $(3.57 \%$ per annum) as warfarin-experienced patients assigned to warfarin. ${ }^{51}$ The RE-LY study did not provide evidence that novel anticoagulants have an additional advantage over warfarin during the initiation period, ${ }^{51}$ and prospective evidence is lacking on effective methods to identify and reduce risk of bleeding during initiation of anticoagulation.

Methods to improve INR control include self-management and computerized decision support. Self-management includes self-testing with a hand-held device that allows patients to measure their INR and then either self-adjust their treatment according to a predetermined dosing schedule or 


\begin{tabular}{|c|c|c|c|c|c|}
\hline \multicolumn{3}{|l|}{ ROCKET-AF } & \multicolumn{3}{|l|}{ ARISTOTLE } \\
\hline $\begin{array}{l}\text { Rivaroxaban } 20 \mathrm{mg} \\
\text { once daily }(708 \mathrm{I})\end{array}$ & $\begin{array}{l}\text { Warfarin } \\
(7090)\end{array}$ & $\begin{array}{l}\text { Rivaroxaban vs } \\
\text { warfarin }\end{array}$ & $\begin{array}{l}\text { Apixaban } 5 \mathrm{mg} \\
\text { twice daily }(9 \mid 20)\end{array}$ & $\begin{array}{l}\text { Warfarin } \\
(9081)\end{array}$ & Apixaban vs warfarin \\
\hline 2.1 & 2.4 & $0.88(0.75-1.03)$ & 1.27 & 1.60 & $0.79(0.66-0.95)$ \\
\hline (I.7 on treatment)* & (2.2 on treatment)* & $0.79(0.66-0.96)^{*}$ & & & \\
\hline $1.65^{*}$ & $1.96 *$ & $0.85(0.70-1.03)^{*}$ & 1.19 & 1.51 & $0.79(0.65-0.95)$ \\
\hline $0.26 *$ & $0.44 *$ & $0.59(0.37-0.93)^{*}$ & 0.24 & 0.47 & $0.51(0.35-0.75)$ \\
\hline $1.40 *$ & $1.52 *$ & Not published & 0.97 & 1.05 & $0.92(0.74-1.13)$ \\
\hline $0.91 *$ & $1.12 *$ & $0.8 \mathrm{I}(0.63-\mathrm{I} .06)^{*}$ & 0.53 & 0.61 & $0.88(0.66-1.17)$ \\
\hline $1.53 *$ & I.7I* & $0.89(0.73-1.10)^{*}$ & Not published & Not published & Not published \\
\hline $1.87 *$ & $2.21 *$ & $0.85(0.70-1.02)^{*}$ & 3.52 & 3.94 & $0.89(0.80-0.998)$ \\
\hline $3.6^{*}$ & $3.4^{*}$ & $1.04(0.90-1.20)^{*}$ & $2.13^{*}$ & $3.09 *$ & $0.69(0.60-0.80)^{*}$ \\
\hline $0.5^{*}$ & $0.7^{*}$ & $0.67(0.47-0.93)^{*}$ & $0.33^{*}$ & $0.80 *$ & $0.42(0.30-0.58)$ \\
\hline
\end{tabular}

Notes: Intention-to-treat analyses unless otherwise stated. Starred resulted were published for patients "on treatment."

contact a health care professional. Systematic reviews of selfmanagement demonstrated that patients who self-monitor and self-adjust their anticoagulation had significantly lower rates of stroke and bleeding, although in half of the studies less than $50 \%$ of eligible patients were able to complete the necessary training. ${ }^{52,53}$ Computer-assisted dosing has similarly been found to nonsignficantly reduce rates of stroke and bleeding, with improved INR control. ${ }^{54}$ Conversely, genotyping - which is appealing, as polymorphisms of the genes for vitamin $\mathrm{K}$ epoxide reductase enzyme (VKORC1) and cytochrome P450 2C9 enzyme are known to affect the metabolism and action of warfarin ${ }^{55}$ - has not been found to result in significant effects on bleeding rates or TTR when used to guide dosing. ${ }^{56}$ Patient safety initiatives to improve standards of training, protocols, patient education, and audit seem likely to improve the efficacy and safety of vitamin $\mathrm{K}$ antagonists. ${ }^{57}$

Improvements in INR control reduce the advantages of novel anticoagulants over warfarin: in the quartile of centers in the RE-LY study that had the highest TTRs $(>72.6 \%)$, annual rates of stroke and systemic embolus were similar between dabigatran $150 \mathrm{mg}$ and warfarin (1.27 vs 1.34 , hazard ratio $[\mathrm{HR}]=0.95 ; 95 \% \mathrm{CI}$ : $0.61-1.48)$, and rates of major hemorrhage were nonsignificantly higher in the dabigatran group (3.60 vs 3.11, HR $=1.16$; $95 \% \mathrm{CI}: 0.88-1.54) .{ }^{58}$

\section{Cost effectiveness of novel anticoagulants versus vitamin $\mathrm{K}$ antagonists}

There are an increasing number of cost-effectiveness analyses that extrapolate from RE-LY study data to compare dabigatran etexilate with warfarin; four of these analyses are summarized in Table 6 . The cost-effectiveness calculated in the these analyses differ substantially due to differing populations (the younger population in Freeman et al has a lower stroke risk), ${ }^{59}$ assumed cost of stroke care (which is estimated to be considerably higher in Sorensen et al than the other two studies), ${ }^{60}$ and cost of the new agent (which is estimated to be highest in Freeman et al).

Analyses found a dabigatran $150 \mathrm{mg}$ BD dose to be more cost effective than a $110 \mathrm{mg}$ BD dose. Pink et al were unable to find a subset of patients in which the lower dose of dabigatran was more cost effective than the higher dose.

The NICE (National Institute for Health and Clinical Excellence, UK) development technology appraisal for dabigatran was released in November 2011 and is shown in Table $6 .{ }^{61}$ The ICER (a measure of the ratio of the increased cost of switching treatment to dabigatran against the gain in quality-adjusted life years) that was calculated was dependent on the cost of warfarin monitoring, which was assumed to be $£ 241.54$ per annum. The cost of dabigatran was assumed to be $£ 2.52$ (excl VAT) per day in the NICE appraisal, which is higher than in the study by Sorensen et al, ${ }^{60}$ but substantially lower than in Freeman et al. ${ }^{59}$

In the subset of patients who have good INR control, dabigatran is not cost effective compared with warfarin, while in those with the best INR control (time in therapeutic range of at least $83.7 \%$ ) the estimated ICER rises to $£ 47,000$ per quality adjusted life year (QALY) gained. ${ }^{61}$

These cost-effectiveness analyses all compare dabigatran to warfarin. One of the major potential advantages of the new 


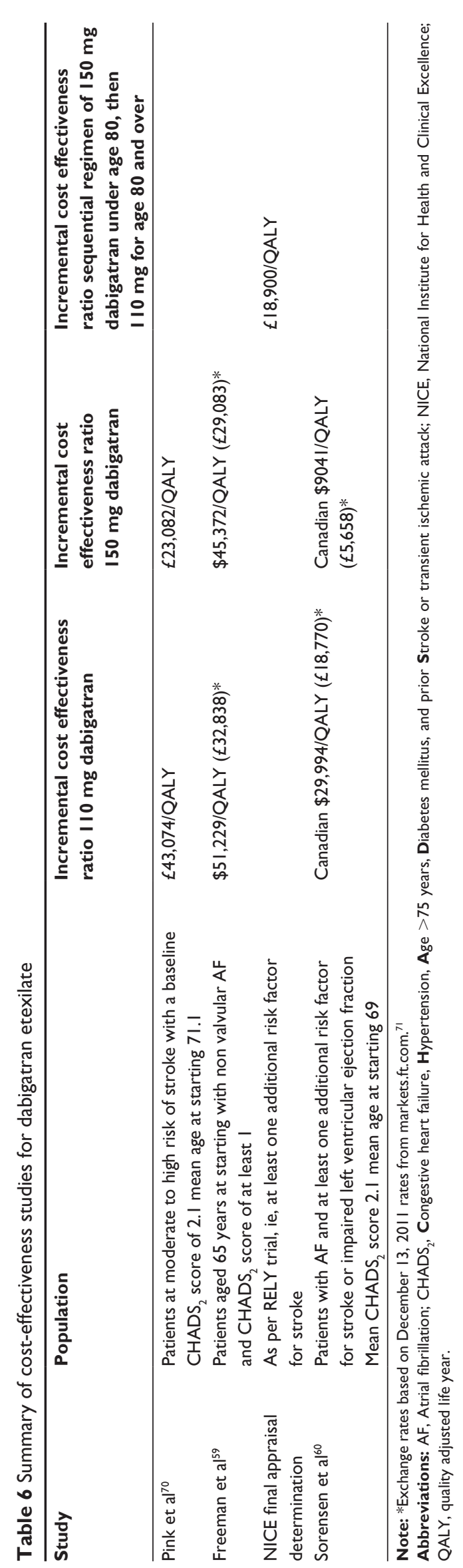

anticoagulants is that they should allow more people to be treated with an anticoagulant than is currently the case. In this instance, the cost-effectiveness analysis would be a new anticoagulant versus nothing, or versus aspirin. Such costeffectiveness analyses have not been carried out, but given the significant improvement in efficacy of the new anticoagulant regime, ${ }^{13}$ use in such fashion is likely to be highly cost effective. The new anticoagulants are cost effective compared to warfarin, and warfarin is cost effective compared to aspirin. ${ }^{62}$

\section{Conclusion}

Recent evidence favors treating a higher proportion of patients with AF with an anticoagulant. Left atrial appendage surgery may be an alternative for some patients, but more research is required to ensure that it is safe and has long-lasting benefits that are reproducible on a population level. Maintenance of sinus rhythm without continued anticoagulation is not an alternative for most high-risk patients, partly due to the low success rate in patients with comorbidities. Antiplatelets should almost never be used in high-risk patients due to the clear superiority of anticoagulants and the increased variety of anticoagulants available to patients with specific intolerances. The general recommendation to use anticoagulation - either a novel agent or a vitamin $\mathrm{K}$ antagonist such as warfarin - is clearer than ever, with the key current debate being the decision over which to use.

Professional guidelines generally predate the ROCKETAF and ARISTOTLE studies and comment on the merits of dabigatran versus vitamin $\mathrm{K}$ antagonists. American and European professional guidelines neutrally permit the use of dabigatran or vitamin K antagonists. ${ }^{18,46}$ Specific judgments about the best dosage of dabigatran have been made, with the US Food and Drug Administration (FDA) not licensing the use of dabigatran $110 \mathrm{mg}$ twice daily on the basis that $150 \mathrm{mg}$ twice daily was more effective at reducing stroke and systemic embolus, and this was the more important outcome (major bleeding, which was lower with $110 \mathrm{mg}$ twice daily, is usually treatable).$^{63}$ Some bodies, such as NICE, take costeffectiveness explicitly into account in their assessments, ${ }^{61}$ and this may lead to a preference to use warfarin as a first-line treatment unless INR control is poor despite good compliance, or warfarin is not tolerated. ${ }^{64}$ Specific situations - such as previous myocardial infarction, high bleeding risk, or renal impairment - will favor one anticoagulant over another, but the range of options is expanded.

A number of questions remain, particularly regarding the superiority of dabigatran and other novels over warfarin 
in nontrial settings that are achieving excellent TTRs, and the safety and efficacy of novel anticoagulants over the long term in non-trial settings. ${ }^{65}$ If many patients are to be tried on warfarin first, it remains unclear at what level of TTR should they be switched, and which patients - perhaps those with high bleeding risk - should skip the warfarin step altogether.

Differences in efficacy between warfarin and the best new anticoagulants are smaller than the differences between anticoagulation and no anticoagulation, so the main benefit of novel anticoagulants will be an increase in treatment options so that a greater proportion of high-risk patients can receive treatment.

\section{Disclosure}

JM has undertaken consultancy work for and received speaker's fees from Boehringer Ingelheim. The authors report no other conflicts of interest in this work.

\section{References}

1. Wolf PA, Abbott RD, Kannel WB. Atrial fibrillation as an independent risk factor for stroke: the Framingham Study. Stroke. 1991;22(8):983-988.

2. Go AS. The epidemiology of atrial fibrillation in elderly persons: the tip of the iceberg. Am J Geriatr Cardiol. 2005;14(2):56-61.

3. Lakshminarayan K, Solid CA, Collins AJ, Anderson DC, Herzog CA. Atrial fibrillation and stroke in the general medicare population: a 10-year perspective (1992 to 2002). Stroke. 2006;37(8): 1969-1974.

4. Miyasaka Y, Barnes ME, Gersh BJ, et al. Secular trends in incidence of atrial fibrillation in Olmsted County, Minnesota, 1980 to 2000, and implications on the projections for future prevalence. Circulation. 2006;114(2):119-125.

5. National Institute for Health and Clinical Excellence. Atrial Fibrillation. London, UK: NICE; 2006.

6. Stroke Risk in Atrial Fibrillation Working Group. Independent predictors of stroke in patients with atrial fibrillation: a systematic review. Neurology. 2007;69(6):546-554.

7. Hughes M, Lip GY, Guideline Development Group, National Clinical Guideline for Management of Atrial Fibrillation in Primary and Secondary Care, National Institute for Health and Clinical Excellence. Stroke and thromboembolism in atrial fibrillation: a systematic review of stroke risk factors, risk stratification schema and cost effectiveness data. Thromb Haemost. 2008;99(2):295-304.

8. Hart RG, Pearce LA. Current status of stroke risk stratification in patients with atrial fibrillation. Stroke. 2009;40(7):2607-2610.

9. Gage BF, Waterman AD, Shannon W, Boechler M, Rich MW, Radford MJ. Validation of clinical classification schemes for predicting stroke: results from the National Registry of Atrial Fibrillation. JAMA. 2001;285(22):2864-2870.

10. Lip GY, Nieuwlaat R, Pisters R, Lane DA, Crijns HJ. Refining clinical risk stratification for predicting stroke and thromboembolism in atrial fibrillation using a novel risk factor-based approach: the euro heart survey on atrial fibrillation. Chest. 2010;137(2): 263-272.

11. Mant J, Hobbs FD, Fletcher K, et al. Warfarin versus aspirin for stroke prevention in an elderly community population with atrial fibrillation (the Birmingham Atrial Fibrillation Treatment of the Aged Study, BAFTA): a randomised controlled trial. Lancet. 2007;370(9586): 493-503.
12. Healey JS, Hart RG, Pogue J, et al. Risks and benefits of oral anticoagulation compared with clopidogrel plus aspirin in patients with atrial fibrillation according to stroke risk: the atrial fibrillation clopidogrel trial with irbesartan for prevention of vascular events (ACTIVE-W). Stroke. 2008;39(5):1482-1486.

13. Connolly SJ, Eikelboom J, Joyner C, et al. Apixaban in patients with atrial fibrillation. $N$ Engl J Med. 2011;364(9):806-817.

14. Devereaux PJ, Anderson DR, Gardner MJ, et al. Differences between perspectives of physicians and patients on anticoagulation in patients with atrial fibrillation: observational study. BMJ. 2001;323(7323):1218-1222.

15. Protheroe J, Fahey T, Montgomery AA, Peters TJ. The impact of patients' preferences on the treatment of atrial fibrillation: observational study of patient based decision analysis. BMJ. 2000;320(7246): $1380-1384$.

16. Hobbs FD, Roalfe AK, Lip GY, et al. Performance of stroke risk scores in older people with atrial fibrillation not taking warfarin: comparative cohort study from BAFTA trial. BMJ. 2011;342:d3653.

17. Olesen JB, Lip GY, Hansen ML, et al. Validation of risk stratification schemes for predicting stroke and thromboembolism in patients with atrial fibrillation: nationwide cohort study. BMJ. 2011;342: d124.

18. European Heart Rhythm Association, European Association for CardioThoracic Surgery, Camm AJ, et al. Guidelines for the management of atrial fibrillation: the Task Force for the Management of Atrial Fibrillation of the European Society of Cardiology (ESC). Eur Heart J. 2010;31(19):2369-2429.

19. Seet RC, Friedman PA, Rabinstein AA. Prolonged rhythm monitoring for the detection of occult paroxysmal atrial fibrillation in ischemic stroke of unknown cause. Circulation. 2011;124(4): 477-486.

20. Healey JS, Connolly SJ, Gold MR, et al. Subclinical atrial fibrillation and the risk of stroke. $N$ Engl J Med. 2012;366(2):120-129.

21. Fuster V, Rydén LE, Cannom DS, et al. 2011 ACCF/AHA/HRS focused updates incorporated into the ACC/AHA/ESC 2006 Guidelines for the management of patients with atrial fibrillation: a report of the American College of Cardiology Foundation/American Heart Association Task Force on Practice Guidelines developed in partnership with the European Society of Cardiology and in collaboration with the European Heart Rhythm Association and the Heart Rhythm Society. J Am Coll Cardiol. 2011;57(11):e101-e198.

22. Wyse DG, Waldo AL, DiMarco JP, et al. A comparison of rate control and rhythm control in patients with atrial fibrillation. $N$ Engl $J$ Med. 2002;347(23):1825-1833.

23. Corley SD, Epstein AE, DiMarco JP, et al. Relationships between sinus rhythm, treatment, and survival in the Atrial Fibrillation Follow-Up Investigation of Rhythm Management (AFFIRM) Study. Circulation. 2004;109(12):1509-1513.

24. Hohnloser SH, Crijns HJ, van Eickels EM, et al. Effect of dronedarone on cardiovascular events in atrial fibrillation. $N$ Engl J Med. 2009;360(7):668-678.

25. Connolly SJ, Camm AJ, Halperin JL, et al. Dronedarone in high-risk permanent atrial fibrillation. $N$ Engl J Med. 2011;365(24):2268-2276.

26. Calkins H, Reynolds MR, Spector P, et al. Treatment of atrial fibrillation with antiarrhythmic drugs or radiofrequency ablation: two systematic literature reviews and meta-analyses. Circ Arrhythm Electrophysiol. 2009;2(4):349-361.

27. Bunch TJ, Crandall BG, Weiss JP, et al. Patients treated with catheter ablation for atrial fibrillation have long-term rates of death, stroke, and dementia similar to patients without atrial fibrillation. $J$ Cardiovasc Electrophysiol. 2011;22(8):839-845.

28. Hunter RJ, McCready J, Diab I, et al. Maintenance of sinus rhythm with an ablation strategy in patients with atrial fibrillation is associated with a lower risk of stroke and death. Heart. 2012;98(1):48-53.

29. Blackshear JL, Odell JA. Appendage obliteration to reduce stroke in cardiac surgical patients with atrial fibrillation. Ann Thorac Surg. 1996;61(2):755-759. 
30. Holmes DR, Reddy VY, Turi ZG, et al. Percutaneous closure of the left atrial appendage versus warfarin therapy for prevention of stroke in patients with atrial fibrillation: a randomised non-inferiority trial. Lancet. 2009;374(9689):534-542.

31. Reddy VY, Holmes D, Doshi SK, Neuzil P, Kar S. Safety of percutaneous left atrial appendage closure: results from the Watchman Left Atrial Appendage System for Embolic Protection in Patients with AF (PROTECT AF) clinical trial and the Continued Access Registry. Circulation. 2011;123(4):417-424.

32. Block PC, Burstein S, Casale PN, et al. Percutaneous left atrial appendage occlusion for patients in atrial fibrillation suboptimal for warfarin therapy: 5-year results of the PLAATO (Percutaneous Left Atrial Appendage Transcatheter Occlusion) Study. JACC Cardiovasc Interv. 2009;2(7):594-600.

33. Hart RG, Pearce LA, Aguilar MI. Meta-analysis: antithrombotic therapy to prevent stroke in patients who have nonvalvular atrial fibrillation. Ann Intern Med. 2007;146(12):857-867.

34. ACTIVE Writing Group of the ACTIVE Investigators, Connolly S, Pogue J, et al. Clopidogrel plus aspirin versus oral anticoagulation for atrial fibrillation in the Atrial fibrillation Clopidogrel Trial with Irbesartan for prevention of Vascular Events (ACTIVE W): a randomised controlled trial. Lancet. 2006;367(9526):1903-1912.

35. Hansen ML, Sørensen R, Clausen MT, et al. Risk of bleeding with single, dual, or triple therapy with warfarin, aspirin, and clopidogrel in patients with atrial fibrillation. Arch Intern Med. 2010;170(16):1433-1441.

36. ACTIVE Investigators, Connolly SJ, Pogue J, et al. Effect of clopidogrel added to aspirin in patients with atrial fibrillation. $N$ Engl J Med. 2009;360(20):2066-2078.

37. Furie KL, Kasner SE, Adams RJ, et al. Guidelines for the prevention of stroke in patients with stroke or transient ischemic attack: a guideline for healthcare professionals from the American Heart Association/ American Stroke Association. Stroke. 2011;42(1):227-276.

38. Lip GY. Don't add aspirin for associated stable vascular disease in a patient with atrial fibrillation receiving anticoagulation. BMJ. 2008; 336(7644):614-615.

39. Hurlen M, Abdelnoor M, Smith P, Erikssen J, Arnesen H. Warfarin, aspirin, or both after myocardial infarction. NEngl J Med. 2002;347(13): 969-974.

40. Connolly SJ, Ezekowitz MD, Yusuf S, et al. Dabigatran versus warfarin in patients with atrial fibrillation. $N$ Engl J Med. 2009;361(12): 1139-1151.

41. Granger CB, Alexander JH, McMurray JJ, et al. Apixaban versus warfarin in patients with atrial fibrillation. N Engl J Med. 2011;365(11): 981-992.

42. Patel MR, Mahaffey KW, Garg J, et al. Rivaroxaban versus warfarin in nonvalvular atrial fibrillation. $N$ Engl J Med. 2011;365(11):883-891.

43. Amadeus Investigators, Bousser MG, Bouthier J, et al. Comparison of idraparinux with vitamin $\mathrm{K}$ antagonists for prevention of thromboembolism in patients with atrial fibrillation: a randomised, open-label, non-inferiority trial. Lancet. 2008;371(9609):315-321.

44. Albers GW, Diener HC, Frison L, et al. Ximelagatran vs warfarin for stroke prevention in patients with nonvalvular atrial fibrillation: a randomized trial. JAMA. 2005;293(6):690-698.

45. Uchino K, Hernandez AV. Dabigatran association with higher risk of acute coronary events: meta-analysis of noninferiority randomized controlled trials. Arch Intern Med. 2012;172(5):397-402.

46. Wann LS, Curtis AB, Ellenbogen KA, et al. 2011 ACCF/AHA/HRS focused update on the management of patients with atrial fibrillation (update on Dabigatran): a report of the American College of Cardiology Foundation/American Heart Association Task Force on practice guidelines. Circulation. 2011;123(10):1144-1150.

47. Pisters R, Lane DA, Nieuwlaat R, de Vos CB, Crijns HJ, Lip GY. A novel user-friendly score (HAS-BLED) to assess one-year risk of major bleeding in atrial fibrillation patients: The Euro Heart Survey. Chest. 2010;138(5):1093-1100.
48. Gage BF, Yan Y, Milligan PE, et al. Clinical classification schemes for predicting hemorrhage: results from the National Registry of Atrial Fibrillation (NRAF). Am Heart J. 2006;151(3):713-719.

49. Cowan C, Fay M, Griffith K, Jenkinson D. Anticoagulation in AF. Anticoagulation uptake remains poor in high risk patients. $B M J$. 2011;342:d1153.

50. Hylek EM, Evans-Molina C, Shea C, Henault LE, Regan S. Major hemorrhage and tolerability of warfarin in the first year of therapy among elderly patients with atrial fibrillation. Circulation. 2007;115(21): 2689-2696.

51. Ezekowitz MD, Wallentin L, Connolly SJ, et al. Dabigatran and warfarin in vitamin $\mathrm{K}$ antagonist-naive and -experienced cohorts with atrial fibrillation. Circulation. 2010;122(22):2246-2253.

52. Heneghan C, Ward A, Perera R, et al. Self-monitoring of oral anticoagulation: systematic review and meta-analysis of individual patient data. Lancet. 2012;379(9813):322-334.

53. Bloomfield HE, Krause A, Greer N, et al. Meta-analysis: effect of patient self-testing and self-management of long-term anticoagulation on major clinical outcomes. Ann Intern Med. 2011;154(7): $472-482$.

54. Poller L, Keown M, Ibrahim S, et al. An international multicenter randomized study of computer-assisted oral anticoagulant dosage vs medical staff dosage. J Thromb Haemost. 2008;6(6):935-943.

55. Aquilante CL, Langaee TY, Lopez LM, et al. Influence of coagulation factor, vitamin $\mathrm{K}$ epoxide reductase complex subunit 1, and cytochrome P450 2C9 gene polymorphisms on warfarin dose requirements. Clin Pharmacol Ther. 2006;79(4):291-302.

56. Kangelaris KN, Bent S, Nussbaum RL, Garcia DA, Tice JA. Genetic testing before anticoagulation? A systematic review of pharmacogenetic dosing of warfarin. J Gen Intern Med. 2009;24(5):656-664.

57. Fairbairn-Smith L, Cope W, Robinson B, Kamali F, Wynne H. Effect of provision of the NHS NPSA oral anticoagulant therapy patient information pack upon patients' knowledge and anticoagulant control. J Thromb Haemost. 2011;9(1):231-233.

58. Wallentin L, Yusuf S, Ezekowitz MD, et al. Efficacy and safety of dabigatran compared with warfarin at different levels of international normalised ratio control for stroke prevention in atrial fibrillation: an analysis of the RE-LY trial. Lancet. 2010;376(9745): 975-983.

59. Freeman JV, Zhu RP, Owens DK, et al. Cost-effectiveness of dabigatran compared with warfarin for stroke prevention in atrial fibrillation. Ann Intern Med. 2011;154(1):1-11.

60. Sorensen SV, Kansal AR, Connolly S, et al. Cost-effectiveness of dabigatran etexilate for the prevention of stroke and systemic embolism in atrial fibrillation: a Canadian payer perspective. Thromb Haemost. 2011;105(5):908-919.

61. National Institute for Health and Clinical Excellence. Dabigatran etexilate for the prevention of stroke and systemic embolism in atrial fibrillation. Available from: http://www.nice.org.uk/nicemedia/ live/12225/56899/56899.pdf. Accessed January 10, 2012.

62. Jowett S, Bryan S, Mant J, et al. Cost effectiveness of warfarin versus aspirin in patients older than 75 years with atrial fibrillation. Stroke. 2011;42(6):1717-1721.

63. Beasley BN, Unger EF, Temple R. Anticoagulant options - why the FDA approved a higher but not a lower dose of dabigatran. $N$ Engl J Med. 2011;364(19):1788-1790.

64. Healthcare Improvement Scotland. Consensus statement for the prevention of stroke and systemic embolism in adut patients with non-valvular atrial fibrillation. Available from: http://www. healthcareimprovementscotland.org/programmes/cardiovascular_disease/dabigatran/dabigatran_consensus.aspx. Accessed January 23, 2012.

65. Jacobs JM, Stessman J. Dabigatran: do we have sufficient data? comment on "dabigatran association with higher risk of acute coronary events". Arch Intern Med. 2012;172(5):403-404. 
66. Ruff CT, Giugliano RP, Antman EM, et al. Evaluation of the novel factor Xa inhibitor edoxaban compared with warfarin in patients with atrial fibrillation: design and rationale for the Effective aNticoaGulation with factor xA next GEneration in Atrial Fibrillation-Thrombolysis In Myocardial Infarction study 48 (ENGAGE AF-TIMI 48). Am Heart J. 2010;160(4):635-641.

67. Connolly SJ, Ezekowitz MD, Yusuf S, Reilly PA, Wallentin L; Randomized Evaluation of Long-Term Anticoagulation Therapy Investigators. Newly identified events in the RE-LY trial. $N$ Engl J Med. 2010;363(19):1875-1876.

68. Hylek EM, Go AS, Chang Y, et al. Effect of intensity of oral anticoagulation on stroke severity and mortality in atrial fibrillation. $N$ Engl J Med. 2003;349(11):1019-1026.
69. ClinicalTrials.gov [homepage on the Internet]. US National Institutes of Health; 2012. Global study to assess the safety and effectiveness of DU-176b vs standard practice of dosing in warfarin in patients with atrial fibillation (Engage AFTIMI48). Available from http://clinicaltrials.gov/ct2/show/NCT00781391?term=ENGAGE-AF+TIMI\&rank=1. Accessed April 24, 2012.

70. Pink J, Lane S, Pirmohamed M, Hughes DA. Dabigatran etexilate versus warfarin in management of non-valvular atrial fibrillation in UK context: quantitative benefit-harm and economic analyses. $B M J$. 2011;343:d6333.

71. markets.ft.com [homepage on the Internet]. The Financial Times Ltd; c2012. Accessed December 13, 2011.

\section{Publish your work in this journal}

Research Reports in Clinical Cardiology is an international, peerreviewed, open access journal publishing original research, reports, editorials, reviews and commentaries on all areas of cardiology in the clinic and laboratory. The manuscript management system is completely online and includes a very quick and fair peer-review system.
Visit http://www.dovepress.com/testimonials.php to read real quotes from published authors. 